\title{
The case of pyridoxine dependent epilepsy misdiagnosed as non-ketotic hyperglycinemia
}

\author{
Hande Gazeteci-Tekin ${ }^{1}$, Melis Demir², Gül Aktan³, Hasan Tekgül ${ }^{3}$, Sarenur Gökben ${ }^{3}$ \\ ${ }^{1}$ Department of Pediatric Neurology, Çiğli Regional Education Hospital, ${ }^{2}$ Department of Metabolic Disorders, Dr. Behcet \\ Uz Children's Training and Research Hospital; ${ }^{3}$ Division of Child Neurology, Department of Pediatrics, Ege University \\ Faculty of Medicine, Izmir, Turkey. E-mail: gazetecihande@yahoo.com.tr \\ Received: 21st October 2018, Revised: 9th December 2018, Accepted: 15th December 2018
}

SUMMARY: Gazeteci-Tekin H, Demir M, Aktan G, Tekgül H, Gökben S. The case of pyridoxine dependent epilepsy misdiagnosed as non-ketotic hyperglycinemia. Turk J Pediatr 2019; 61: 599-603.

Pyridoxine-dependent epilepsy (PDE) is a rare but an important condition, since early diagnosis and treatment result in normal or near normal psychomotor development. It is caused by mutations in the Antiquitin (ALDH7A1) gene. Different clinical findings may appear in the deficiency of pyridoxine, which is the cofactor of many enzymes. A wide variety of clinical and laboratory findings can cause confusion during diagnosis. We present a male with neonatal convulsions; structural brain anomaly, hyperglycinemia in CSF/plasma, with ALDH7A1 Compound heterozygote mutation.

Key words: b6 deficiency, non-ketotic hyperglycinemia, corpus callosum hypoplasia, burst suppression.

Pyridoxine dependent epilepsy (PDE) is an autosomal recessive epileptic encephalopathy that occurs during the neonatal period. This disease is resistant to classical antiepileptic drugs and is treated with highdose B6. Classically, seizures are responsive to intravenous administration of high-dose pyridoxine. ${ }^{1}$ But sometimes repeat dosages may be needed or small dosages be enough for the cessation of seizures. ${ }^{2,3}$ Seizures usually recur in 1-51 days after pyridoxine is discontinued. ${ }^{2}$ Generalized seizures, atonic, myoclonic seizures, partial seizures and infantile spasms may occur in pyridoxinedependent epilepsy. Hypsarrhythmia, burst suppression, focal spike waves and normal EEG patterns can be recorded. ${ }^{4}$

Neonatal form of non-ketotic hyperglycinemia $(\mathrm{NKH})$ is the most severe form. Clinical and laboratory findings of transient $\mathrm{NKH}$ is indistinguishable from the classic neonatal type. The delay of maturation in the glycine cleavage system is blamed. ${ }^{5,6}$ Transient NKH which can resolve spontaneously in a few months, is thought to be caused by seizures, hypoxia and ischemia starting intrauterine. ${ }^{7}$
We aimed to present an infant with intractable epilepsy mimicking $\mathrm{NKH}$ who was treated for one year before being diagnosed with PDE.

\section{Case Report}

After uncomplicated pregnancy and delivery, the child was born $3200 \mathrm{gr}$ at $39^{\text {th }}$ week of gestation. His mother didn't notice any abnormal repetitious movement during pregnancy. Family history was unremarkable. Ten hours after birth hiccup-like seizures began and he was diagnosed with status epilepticus, phenobarbital bolus was administered intravenously. Intravenous conventional drug treatment stopped the seizures and then phenobarbital $(4 \mathrm{mg} / \mathrm{kg} /$ day $)$ was administered orally. Seizures resumed on the 3rd day after birth with focal status. Fenitoin and levetiresetam were administered intravenously and seizures stopped again. Routine laboratory findings such as glucose level, serum ammonia, calcium level, blood cell count were normal. Lumbar puncture was performed and cerebrospinal fluid (CSF) findings were within normal range in terms of 
protein, glucose levels and cell count. However, CSF glycine level $220 \mu \mathrm{M} / \mathrm{L}$ (reference value,3-20) and plasma level $687.5 \mu \mathrm{M} / \mathrm{L}$ (reference value, 115-600) were increased and the ratio of CSF to plasma glycine was 0.32 (normal<0.02).

Electroencephalography (EEG) showed a burst suppression pattern in first week of life. After the treatment, the patient's burst-suppression pattern improved (Fig. 1-2).

Cranial magnetic resonance imaging revealed cerebral and cerebellar atrophy, a thin corpus callosum, and a subdural effusion (Fig. 3). The analysis of plasma amino acids levels was compatible with NKH. In addition to antiepileptic drugs, oral benzoate and dextromethorphan were administered and his seizures stopped. After a week when he was 3 months old, he was discharged.

The patient was admitted to the hospital with the diagnosis of fever-triggered status epilepticus one month later after discharged. Clonazepam and vigabatrin were added to the patients treatment due to the ongoing seizures. After a two-week seizure-free period he hospitalized in the intensive care unit with status epilepticus which needed anesthetic agents for treatment. After 15 days in the intensive care unit, convulsions stopped by

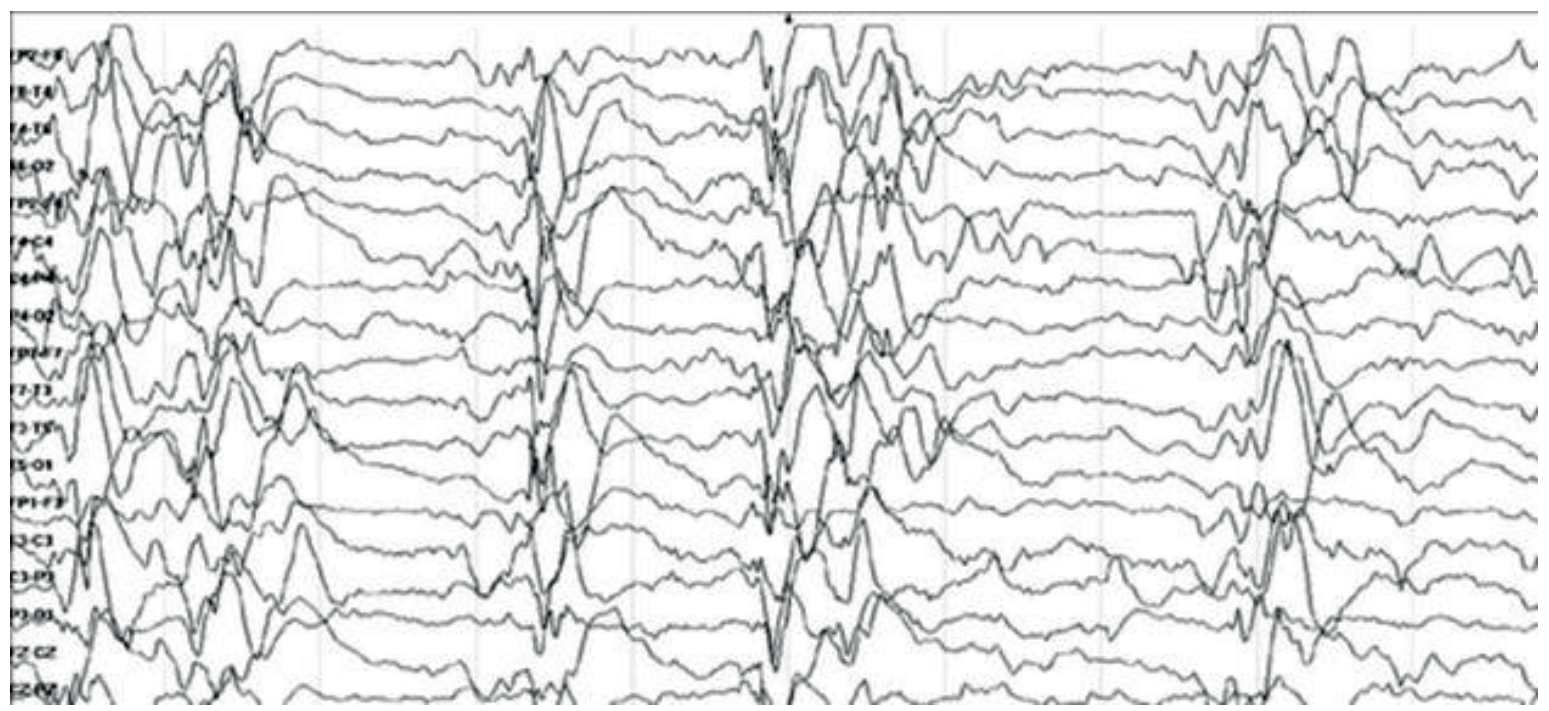

Fig. 1. Pre-treatment EEG: burst-suppression.

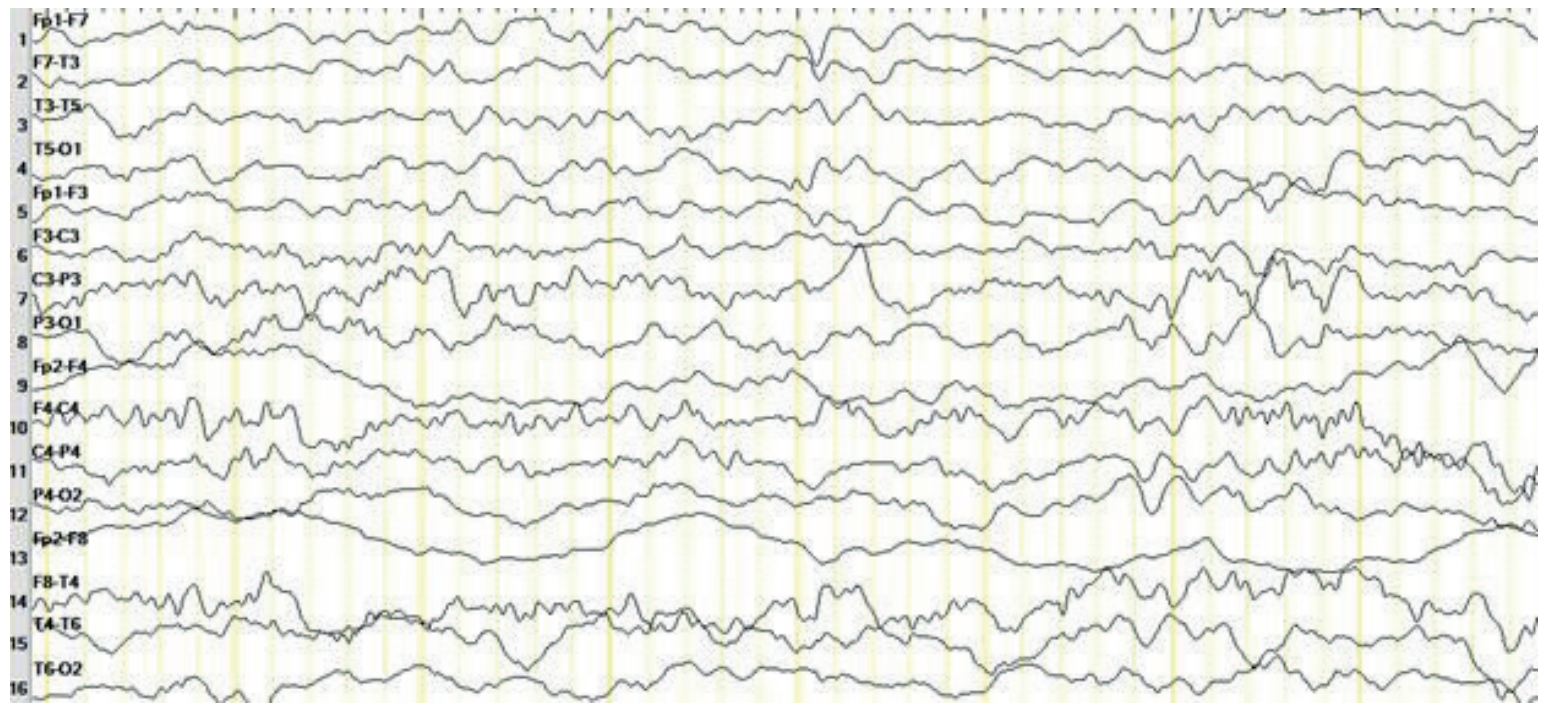

Fig. 2. Post-treatment EEG. 


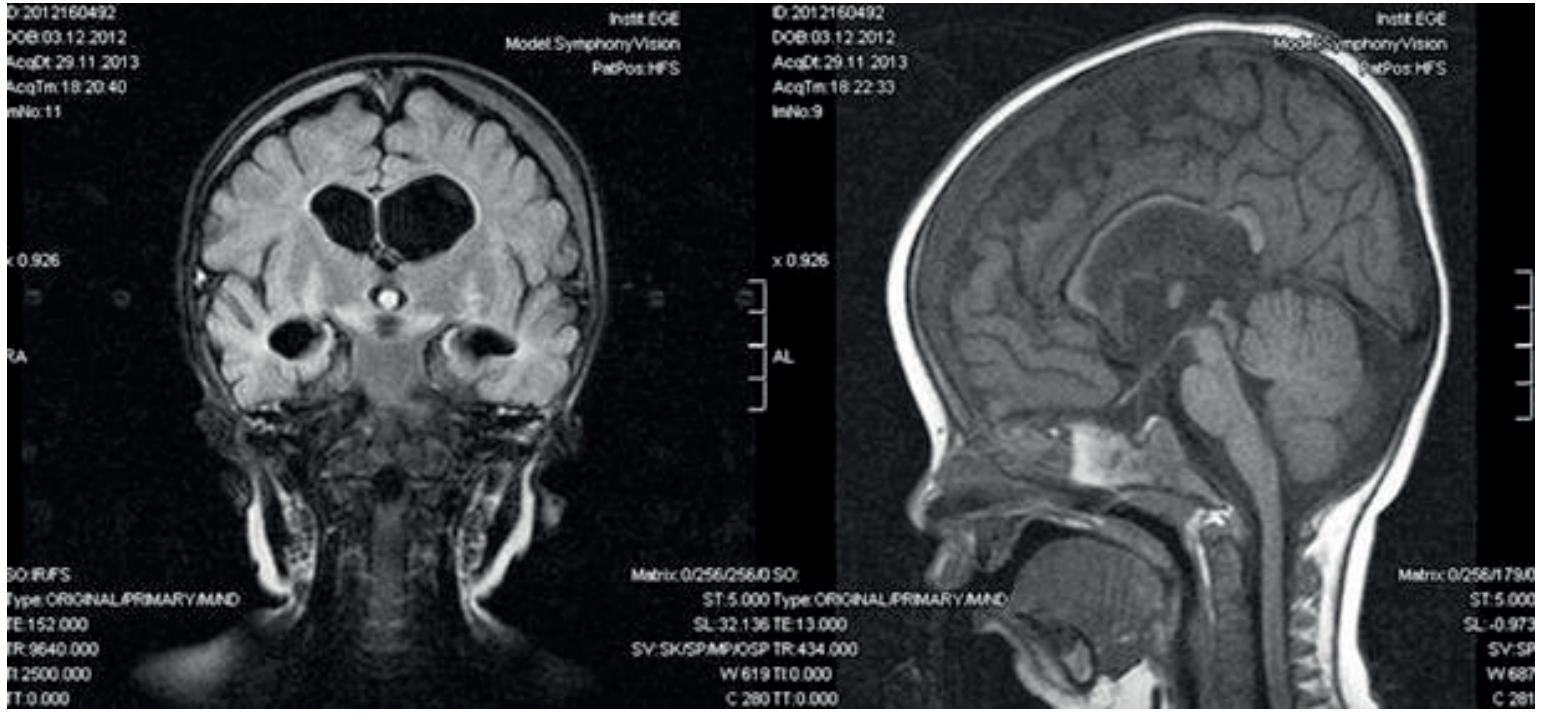

Fig. 3. Cerebral-cerebellar atrophia, thin corpus callosum, subdural effusion.

adding B6 vitamin 30mg/kg/d per orally. Gene analysis revealed compound heterozygous mutations p.r110 (c.328c > T) / IVS17-1G> $\mathrm{T}$ (c.1566-1G> T) in ALDH7A1 gene. At 7 months of age, he was discharged without even holding the head.

At his evaluation at 1 years of age, he had severe hypotonia, severe intellectual disability and motor delay, he could hold his head and sit with support. Since the initiation of the vitamin $\mathrm{B} 6$ he was seizure free without any other antiepileptic agent.

During follow-up at 18 months of age, he was able to sit without support and walk by holding his hands. He could say only one word. At 24 months of age, he could walk by self, but fall easily, use two to four words with meaning and understand a few simple commands.

An informed consent form was obtained from the parents for publishing the case.

\section{Discussion}

PDE usually presents in the neonatal period even in first days of life. Neonatal convulsions may develop due to different etiologic factors such as neurometabolic diseases, structural brain anomalies, hypoxia and acute metabolic changes. It is difficult to establish the etiologic reason immediately. Clinical clues are needed for the diagnosis of patient without hypoxia and metabolic disorders in neonatal convulsions. But sometimes these clues can mislead us.

Certain biomarkers such as elevated levels of pipecolic acid in plasma and CSF have been reported in PDE. Additionally, urinary L- $\alpha-$ aminoadipic semialdehyde ( $\alpha$-AASA) elevation can be used as a good marker for detecting PDE. ${ }^{8,9}$ However, none of these markers are gold standard for diagnosing this disorder, so it can lead to false positive results.

Pyridoxal phosphate which is an active form of pyridoxine may be attributed as cofactor in more than 140 enzymatic reaction. ${ }^{10}$ It explains the presence of various metabolic derangements and different phenotypes in PDE. Lactic acidosis, hypoglycemia, abnormal CSF and plasma amino acid concentrations might be seen in cases with PDE and cause misdiagnosis. ${ }^{1,8,9}$ Seizures increase the level of glycine and intrauterine onset pyridoxine dependent seizures may have elevated glycine levels. ${ }^{5}$

Maeda et al. $^{7}$ reported a case of transient $\mathrm{NKH}$ with similar features. They thought that seizures due to pyridoxine deficiency may trigger hypoxia and increase glycine. Our case had elevated glycine levels in both serum and CSF and he was wrongly diagnosed with $\mathrm{NKH}$.

It should be kept in mind that the levels of plasma and CSF amino acid levels may change after the addition of antiepileptics. 
Phenobarbital inhibits GABA-A receptors like the benzodiazepines. ${ }^{12}$ It has been shown that thiazolum, a short-acting benzodiazepine, elevates glycine in rat brains. ${ }^{13}$ Vigabatrin, an another antiepileptic that acts on GABA, has been shown to cause worsening in patients with $\mathrm{NKH} .{ }^{14}$ With this mechanism, phenobarbital may cause increased glycine levels. In our patient, CSF sampling was done after the start of antiepileptic therapy, which may have changed the glycine level. The onset of seizures in our case is compatible with the typical PDE. But his seizures partially respond to phenobarbital.

Burst-suppression pattern on EEG is not a distinctive finding neither in PDE nor NKH. Reported seizure types are clonic, myoclonic, partial, generalized, infantile spasms, status epilepticus and associated with febrile illness. ${ }^{8,9}$ Our patient had infantile spasms, status epilepticus with febrile illness and generalized seizures.

A wide variety of structural brain anomalies and progressive ventriculomegaly can be seen in PDE cases. ${ }^{15}$ Our case had cerebral and cerebellar atrophy, a thin corpus callosum, and a subdural effusion on cranial MRI. The presence of brain abnormality does not exclude vitamin B6 deficiency.

After the use of B6, there were no further convulsion. Neurodevelopmental delay continues despite the seizure free period. In PDE in spite of effective seizures treatment neurocognitive delay continues in approximately $70 \%$ of cases. This delay is caused by either brain damage in the pretreatment period or by the lytic effects of increased lysine in these patients. In one study, it was shown that the lysine restriction may improve the development of PDE cases. ${ }^{16}$ If lysine restriction is added to the treatment of vitamin B6, the neurological development of patients may be better.

Our case was misdiagnosed as NKH due to very high levels of hyperglycinemia in plasma and CSF, early response to antiepileptic treatment, corpus callosum agenesis and hiccup-like seizures. PDE should be kept in mind in intractable neonatal and infantile seizures and metabolic alterations should be evaluated carefully.

\section{REFERENCES}

1. Stockler S, Plecko B, Gospe SM Jr, et al. Pyridoxine dependent epilepsy and antiquitin deficiency: clinical and molecular characteristics and recommendations for diagnosis, treatment and follow-up. Mol Genet Metab 2011; 104: 48-60.

2. Bass NE, Wyllie E, Cohen B, Joseph SA. Pyridoxinedependent epilepsy: the need for repeated pyridoxine trials and the risk of severe electrocerebral suppression with intravenous pyridoxine infusion. J Child Neurol 1996; 11: 422-424.

3. Grillo E, da Silva RJ, Barbato JH Jr. Pyridoxinedependent seizures responding to extremely lowdose pyridoxine. Dev Med Child Neurol 2001; 43: 413-415.

4. Plecko B, Stöckler S. Vitamin B6 dependent seizures. Can J Neurol Sci 2009; 36(Suppl 2): S73-S77.

5. Aliefendioğlu D, Aslan AT, Coskun T, Dursun A, Cakmak FN, Kesimer M. Transient nonketotic hyperglycinemia: two case reports and literature review. Pediatr Neurol 2003; 28: 151-155.

6. Tada K, Kure S, Takayanagi M, Kume A, Nrisawa K Non-ketotic hyperglycinemia: A life-threatening disorder in the neonate. Early Hum Dev 1992; 29: 75-81.

7. Maeda T, Inutsuka M, Goto K, Izumi T. Transient nonketotic hyperglycinemia in an asphyxiated patient with pyridoxine-dependent seizures. Pediatr Neurol 2000; 22: 225-227.

8. Mills PB, Footitt EJ, Mills KA, et al. Genotypic and phenotypic spectrum of pyridoxine-dependent epilepsy (ALDH7A1 deficiencey). Brain 2010; 133(Pt 7): 2148-2159.

9. Van Karnebeek CD, Tiebout SA, Niermeijer J, et al Pyridoxine-dependent epilepsy: an expanding clinical spectrum. Pediatr Neurol 2016; 59: 6-12.

10. Stöckler-Ipsiroglu S, Van Karnebeek CDM. Pyridoxine and pyridoxal-phosphate dependent epilepsies. In: Hoffmann GF, Blau N, (eds). Congential Neurotransmitter Disorders. Nova Science Publishers; 2014: 149-166.

11. Mercimek-Mahmutoglu S, Horvath GA, CoulterMackie $M$, et al. Profound neonatal hypoglycemia and lactic acidosis caused by pyridoxine-dependent epilepsy. Pediatrics 2012; 129: e1368-e1372.

12. Pacifici GM. Clinical pharmacology of phenobarbital in neonates: effects, metabolism and pharmacokinetics. Curr Pediatr Rev 2016; 12: 48-54. 
13. Aburawi SM, Ahmed SS, Elhwuegi AS, Saad SF, Attia AS. Brain glycine levels in triazolam-treated albino rats. J Neural Transm (Vienna) 2001; 108: 527-539.

14. Tekgul H, Serdaroğlu G, Karapinar B, et al. Vigabatrin caused rapidly progressive deterioration in two cases with early myoclonic encephalopathy associated with nonketotic hyperglycinemia. J Child Neurol 2006; 21: 82-84.
15. Baxter P, Griffiths P, Kelly T, Gardner-Medwin D. Pyridoxine-dependent seizures: demographic, clinical, MRI and psychometric features, and effect of dose on intelligence quotient. Dev Med Child Neurol 1996; 38: 998-1006.

16. Van Karnebeek CD, Hartmann H, Jaggumantri S, et al. Lysine restricted diet for pyridoxine-dependent epilepsy: first evidence and future trials. Mol Genet Metab 2012; 107: 335-344. 